\title{
Forum Posting Habits and Attainment in a Dual-Mode MOOC
}

\author{
D. F. O. Onah, J. E. Sinclair, R. Boyatt \\ Department of Computer Science \\ The University of Warwick, United Kingdom
}

\begin{abstract}
Discussion forums in massive open online courses (MOOCs) are a primary means of interaction among learners and instructors. Despite their widespread use there is concern that forums are not an effective means of promoting engagement and learning. This paper examines issues relating to forums through a brief literature review and by drawing on data from a specific MOOC run by the University of Warwick. Two parallel delivery modes allow comparison of forum participation. We analysed two users; those who contributed to forums and those who did not, using comparison of their final average grades in quizzes to analyse their performance rate. We classified super posters in our CfT forum as those who started a thread or more and at the same time contributed optionally in forum discussion posted by other participants. It was observed in our analyses that participants in the forum perform better within the top grades at the end of the course. However, results indicated that forum use overall is low and that tutor-moderation may close down participants' discussion, while peer-support forums fail to offer adequate support.
\end{abstract}

\section{Introduction}

Discussion forums have been used as online learning tools since the early 1990s and are intended to increase engagement, motivation and reflection, thus leading to deeper learning. Earlier studies have indicated that forums do not support learning as well as might be hoped [1] and that many students resist engagement. The rise of the Massive Open Online Course (MOOC) [2] has underlined the need to support collaborative learning. Despite the concerns, forums have become one of the main tools in many MOOC platforms. However, the common MOOC model allows many thousands of students to each instructor, so forums also take on a major role in both peer-to-peer and tutor-led support.

There are some measures we applied to classified the participants in our forum. Super postal is considered as one of the measure of grouping those who started a thread and contributed in one or more threads. Here we did not distinguish the single thread and the additional reply comments attached to some post. We considered all those that started a post and the other optional comments they made to other posts.

As more MOOC evaluation is conducted, patterns of forum use and issues relating to both social and educational expectations are emerging. The learners' perspective is also evidenced through learning blogs and the forum posts themselves. This paper first briefly reviews literature relating to forum use in MOOCs. Data from the Computing for Teachers (CfT) MOOC is then presented. Developed at the University of Warwick, CfT was run in two parallel modes allowing direct comparison of peer-supported and tutor-supported forums.

Finally, in our conclusion we discuss issues arising and future research directions.

\section{Literature review}

Forums play a central role in most platforms, with diverse expectations including increasing engagement, promoting deep learning, maintaining motivation and decreasing risk of dropout [1]. With large numbers of learners and few instructors, peer communication, support and assessment are seen as key elements of MOOC pedagogy. Completing learners are likely to have made more forum posts than non-completers, and forum posting has been cited as an effective measure of student engagement [3]. Despite this correlation, Baxter and Haycock [4] found that although forums facilitate academic integration, they could have a negative effect on student motivation and online identity. At the most basic level, forums are not good at managing high volumes of posts, with topics becoming fragmented over many threads and a lack of search facilities. McGuire observes that forums attract the majority of learner complaints and may be a deterrent to many [5]. Fini [6] found that learners gravitate towards more passive tools, either through preference or lack of time.

Forum discussions often involve a minority of course members, with threads being dominated by a small number of vocal students. Negative and illmannered posting is a disincentive to some learners 
[7]. Schweizer's account of MOOC participation acknowledges the benefit of forum discussion for promoting reflection but expresses frustration at the general level of contribution as being "unfocused, tentative, and frankly, misinformed" [8]. Peer suggestions and answers may be incorrect and counter-productive for the questioner. Course tutors use forums to provide course information, generate discussion and support learners by answering questions. Brinton et al., observed that active tutor participation increased the discussion volume but did not slow down the decline in participation [9]. However, in other studies tutor participation did not prompt increase forum activity [10].

Yang et al., [11] used social network techniques to investigate forum posts in a Coursera MOOC and concluded that high post duration (time between first and last posts) was related to a lower likelihood of dropout in any given week, whereas being a discussion initiator or making a high amount of posts was not. However, other studies [12,13] provide contradictory evidence, as high levels of posting did appear to correlate with better course outcomes.

The difficulty of effective interaction in large forums has been noted by many authors $[1,3,14]$. In addition to the organisation of large numbers of posts, language is one obvious barrier. Despite the intention of forums making discussions open to all, Yang et al., [11] suggest that "cliquishness" may be essential in forming sub-groups for effective learning support.

Several studies have analysed participants' behaviour in MOOC forums [14]. Forum posters tend to be young, well-educated professionals from the Western world and discussions occur between fairly random crowds rather than encouraging specific study groups [15]. Huang et al., [12] identify the "super-posters" who contribute heavily to the forum and conclude that such behaviour has a positive effect on forum health.

Some MOOCs have made forum participation a required part of the course. However, some learners may not be comfortable with this [10] and it may also lead to a large number of pointless posts. Even for active forum posters, perceived value of forum discussion has been observed to decrease as the MOOC progresses [16]. Despite widespread use of discussion forums in MOOCs and an increasing amount of literature, there is still a lack of clarity over what they are aiming to do and what they are achieving. Evaluation studies so far provide conflicting evidence on a number of aspects and further work is needed to determine best practice for their use and explore alternatives.

\subsection{Super posters in forums}

Haung et al. characterize super posters to based on the measure of the quantity and quality of a user's contributions in the forum [12]. Super posters in a course as mentioned by Haung et al., are a set of users who belongs to the top $5 \%$ of forum participants in a course with high scores. As noted by Coetzee et al., [17], frequent forum posters have high retention as compare to poor retention from non-forum users, which eventually "skews their final grade distribution, with $78 \%$ receiving zeroes,"[17]. Cheng et al., argued that students who participate voluntarily in forums perform better and obtained higher examination grades [18].

\section{Computing for teachers forums}

The Computing for teachers (CfT) MOOC was developed by the Department of Computer Science at Warwick University, UK. It aims to support teachers of computer science in UK schools where a new computing curriculum is being introduced creating a demand for more teachers of computing. CfT covered three areas: Python programming, computing concepts and teaching computing. The first run of the course in 2013/14 attracted over 500 participants, although some of those who registered did not participate in the course. Students were offered a choice between two modes: peer-supported and tutor-supported. The former used "traditional" MOOC forums, mainly intended for students to discuss ideas and answer each other's questions, but with occasional tutor intervention.

The latter provided an additional forum, which was monitored by tutors to provide support as needed, including rapid and (largely) definitive answers to questions. There was a (modest) charge for the tutor-supported mode, which included further "extras" such as weekly online tutorial sessions and a human-marked final programming assignment with individual feedback.

The two parallel modes of the CfT MOOC provide the opportunity for direct comparison of features across different modes. The sample discussion and graphs below give some initial insight into usage of the forums in the two modes.

\subsection{Peer support discussion forums}

These discussion forums were open to all CfT participants. They were unmoderated and covered general issues, programming, concepts and teaching respectively. Snapshots of three of the forums are given in Figures 1, 2 and 3 giving an indication of threads introduced. Aside from introductions and thanks to the course team, the main topics of discussion in the general forum concern programming and course-related issues such as reporting problems and suggesting additions. The dedicated programming forum had a much higher volume of posts than the concepts forum, with the teaching forum being very little used. In general, the 
number of responses was low, with some topics eliciting no replies. Although tutors provided a basic level of monitoring to answer specific questions, some posts, participants (as in Figure 4) expressed a feeling that lack of response hindered their studies. As reported in previous MOOCs, when the level of difficulty increases, too few participants feel confident enough to reply to the confused majority. The tutor's post in this extract points to the further problem that participants can become very spread across the stages of the course. Particularly in a small course this can leave even fewer students in the vanguard who can contribute to discussion of the most recent stages.

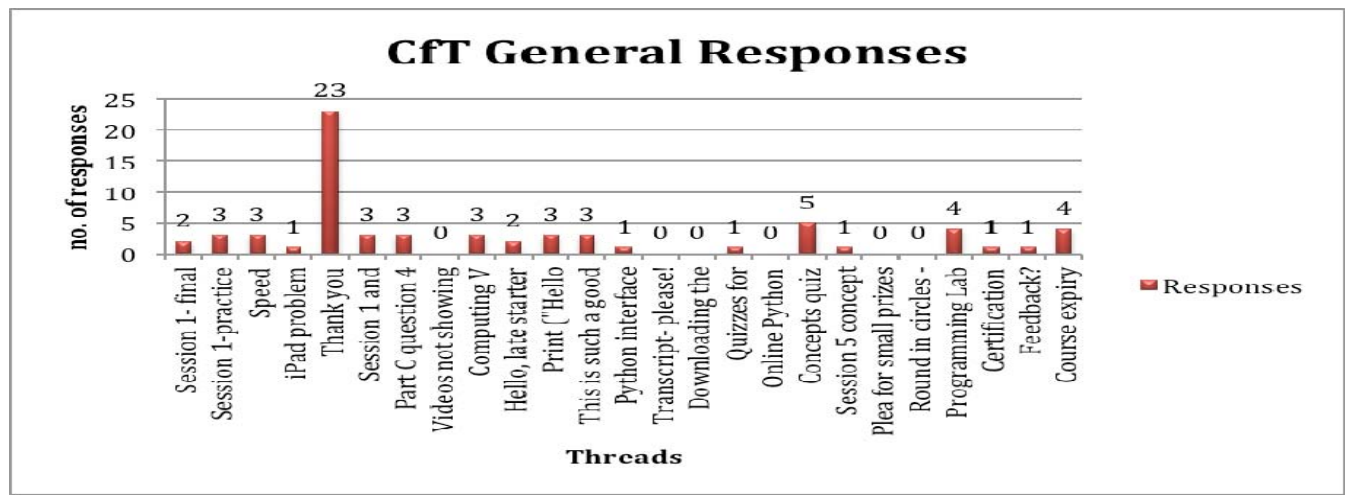

Figure 1. Snapshot of posts to the general peer-supported forum from the Computing for Teachers MOOC

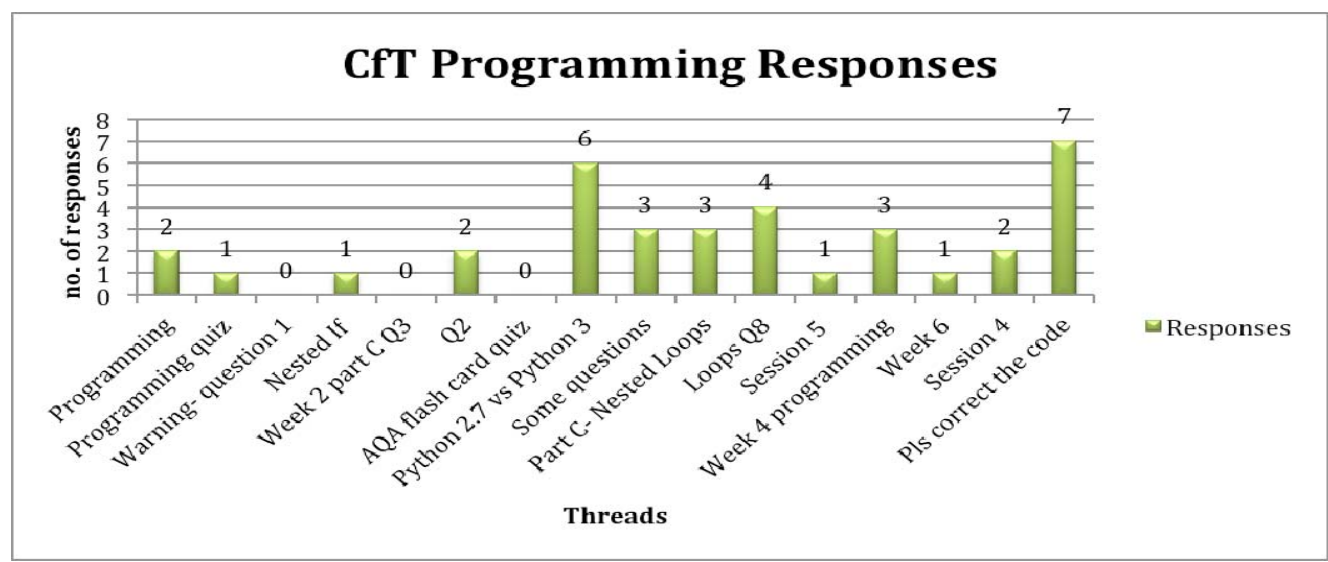

Figure 2. Snapshot of posts on Python programming forum

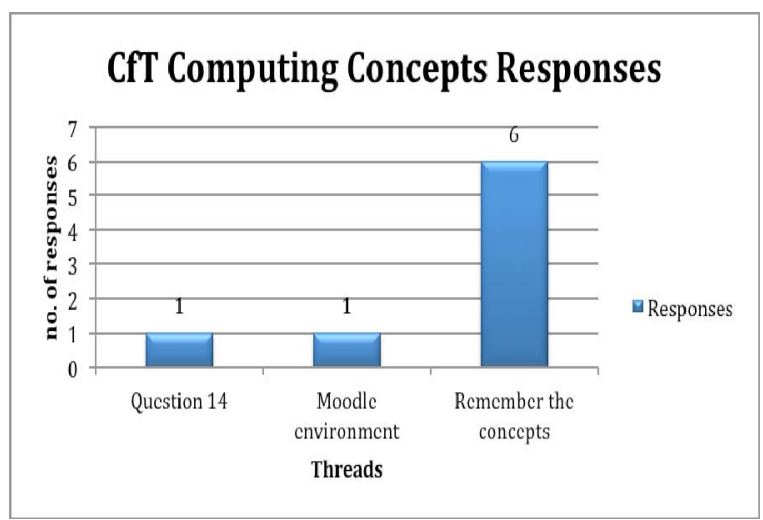

Figure 3. Snapshot of posts on computing concepts

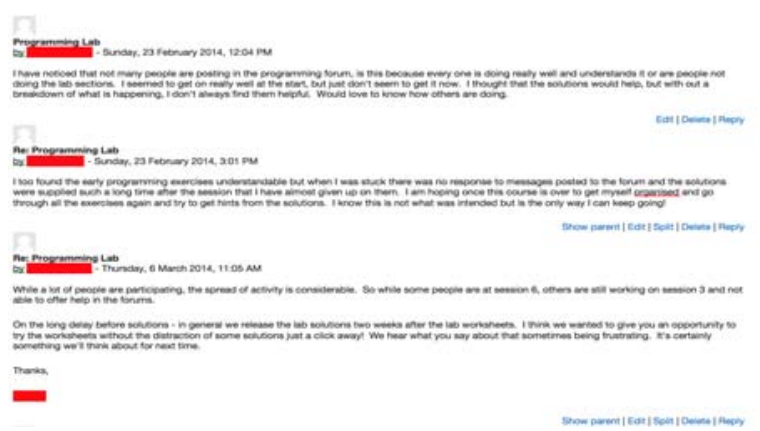

Figure 4. Extract from peer-supported general forum

\subsection{Tutor-monitored forum}

This forum was accessible by students of the tutor-supported mode only. It was intended for providing rapid and informed responses by course 
tutors to targeted questions and problems raised by participants. As can be seen by the extract shown in Figure 5, a query (raised on a Saturday) was answered by a tutor in just over an hour.

The student then shares an approach that they have been working on, but in general, the forum was used by students to obtain direct answers rather than to discuss different approaches or for collaborative problem solving. Figure 6 shows a snapshot of responses to threads in the tutor-supported forum. Here, posts are even less likely to start an on-going discussion, but generally end immediately with either a tutor's response or a corresponding "thank you" message.

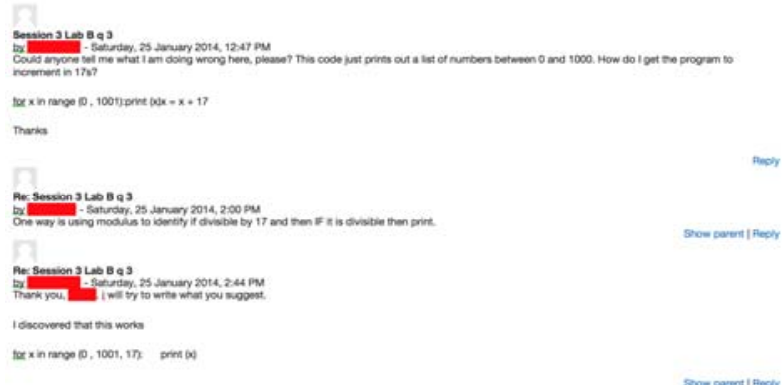

Figure 5. Screenshot of tutor supported forum

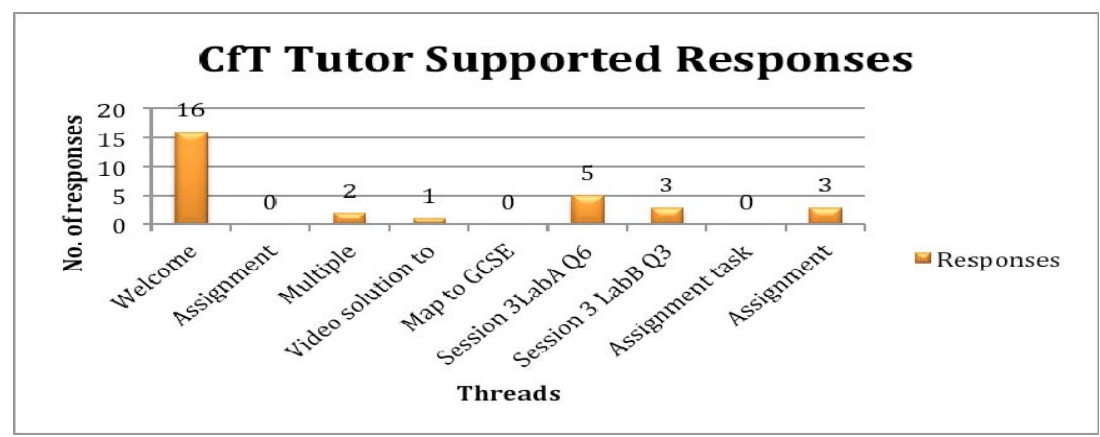

Figure 6. Snapshot of posts from tutor supported forum

\subsection{CfT Forum Evaluation}

Forum discussions mostly are found to contain questions from learners either new or existing thread starters wanting to acquire more knowledge and information about particular course components. CfT forums are not an exception; there exists very little discussion and contributions. Some super posters are observed to have been contributing several times within the forums. We observed that majority of the supper posters in a forum are identified in other forums. For example, a supper poster in general discussion forum can be identified in computing concept and so on. In one of our recent papers [19], Figures 7 and 8 shows that teaching computing thread has the least discussion of 1 thread started with 5 (4\%) contributed.

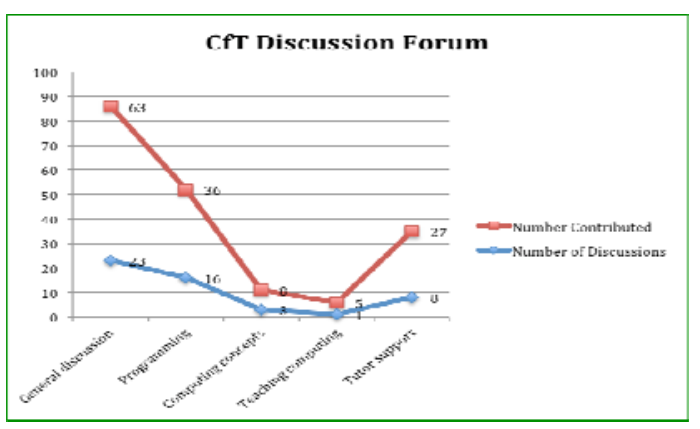

Figure 7. Discussion forum showing number of threads and contributions
The general discussion forum registered the highest volume of contributions of 63 (45\%) with 23 threads as seen in (Figure 7 and Figure 8).

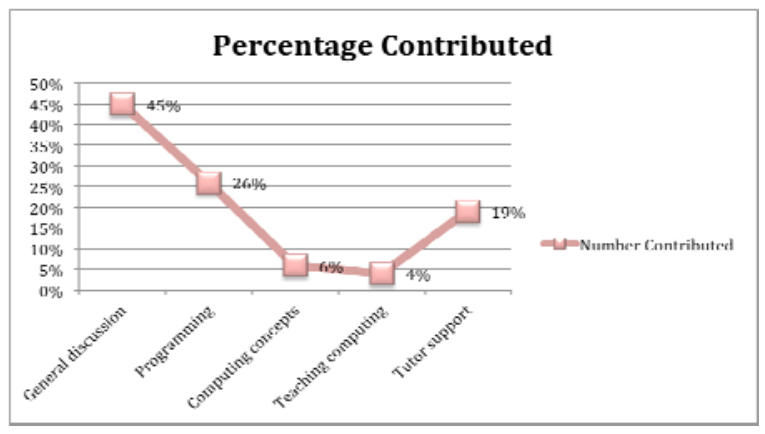

Figure 8. Percentage of contribution in the discussion forum

3.3.1. Individual forum support. Discussion forum in CfT MOOC revealed individual supports received from peers within the course units as illustrated in Figure 9. We observed a thread starter asking for pointer to other materials online which can support their activities and progress within the course. Though some of these requests might not be in conjunction with the current trend of teaching within the course concepts. The post received about 6 responses including the initial thread. 


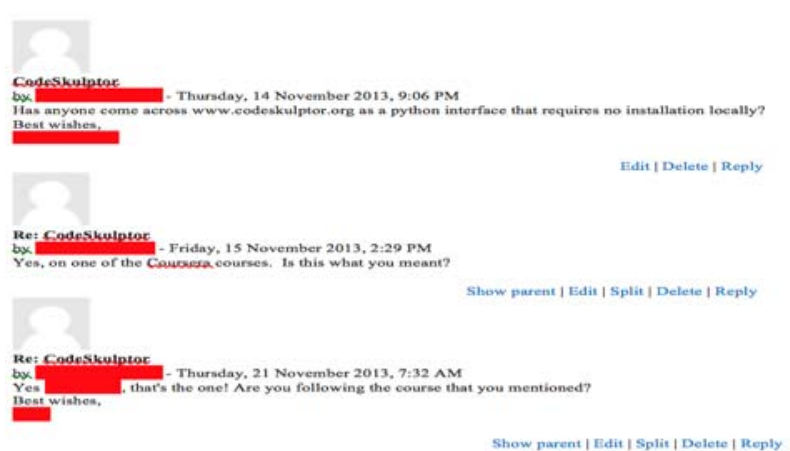

Figure 9. Individual forum supports

3.3.2. Thread initiators in CfT forum. We observed that some thread starters never engage with the quizzes for us to investigate if they completed the course. However, this did not conclude that they were not participating. As explained in one of our recent papers [14], we mentioned how some learners continue participating in the courses at their own pace and time even when the sessions were over.

Our empirical observation in Table 1 shows that each learner posted an initial thread of 1 or more, and also contributed to other discussions at least once. This analysis is centred on participants that started a thread and also actively contributing to other threads started by others in the discussion forums. As the course sessions progresses, quiz participation started declining amount those that were low contributors, the course grades started dropping in each sessions due to lack of participation in the quiz questions [19].

The downside of these behaviour is that learners acquire better grades while participating within the first two sessions' quizzes, but afterwards learners with just one post started declining in grades as the course progresses, shown in Table 1 and Figure 10.

Table 1 illustrated all the participants from both modes (peer-peer supported \& tutor supported) within CfT MOOC forum. The average grade is calculated using the sum of each session's quizzes per user within the forum posts. Each user is anonymously identified to each of the 7 course sessions investigated.

\section{Tutor forum post}

Table 2 is an anonymous identification, which reveals that the dominant high grades were registered within the tutor supported mode forum; with the highest grade seen in user12 $(91.31 \%)$ and the lowest grade is user29 (35.71\%). We carried out the identification to obtain the number of users and performance ratio in each mode in the table (as shown in Table 1 and 2).
Table 1. Users forum participations reveal better grades within the supper-posters and low grades within minima contributors

\begin{tabular}{|c|c|c|c|}
\hline User & $\begin{array}{l}\text { No. of Thread } \\
\text { Started }\end{array}$ & $\begin{array}{c}\text { No. of } \\
\text { forum post } \\
+ \text { thread } \\
\text { started } \\
\end{array}$ & $\begin{array}{c}\text { Average } \\
\text { course grade } \\
(\%) \\
\end{array}$ \\
\hline user1 & 4 & 7 & $22.14 \%$ \\
\hline user2 & 3 & 7 & $67.38 \%$ \\
\hline user3 & 1 & 3 & $87.97 \%$ \\
\hline user4 & 1 & 2 & $79.16 \%$ \\
\hline user5 & 3 & 5 & $0 \%$ \\
\hline user6 & 1 & 1 & $39.76 \%$ \\
\hline user7 & 1 & 1 & $27.14 \%$ \\
\hline user8 & 1 & 1 & $9.28 \%$ \\
\hline user9 & 1 & 1 & $26.42 \%$ \\
\hline user10 & 6 & 8 & $67.02 \%$ \\
\hline user11 & 1 & 1 & $0 \%$ \\
\hline user12 & 2 & 4 & $91.31 \%$ \\
\hline user13 & 2 & 3 & $12.85 \%$ \\
\hline user14 & 1 & 1 & $26.42 \%$ \\
\hline user15 & 1 & 1 & $41.66 \%$ \\
\hline user16 & 2 & 12 & $90 \%$ \\
\hline user17 & 3 & 10 & $87.38 \%$ \\
\hline user18 & 1 & 1 & $25.71 \%$ \\
\hline user19 & 1 & 1 & $0 \%$ \\
\hline user20 & 1 & 2 & $59.52 \%$ \\
\hline user21 & 1 & 2 & $77.85 \%$ \\
\hline user22 & 4 & 5 & $86.07 \%$ \\
\hline user23 & 1 & 13 & $80.59 \%$ \\
\hline user24 & 1 & 2 & $0 \%$ \\
\hline user25 & 1 & 2 & $20 \%$ \\
\hline user26 & 1 & 1 & $45.71 \%$ \\
\hline user27 & 2 & 4 & $61.31 \%$ \\
\hline user28 & 1 & 5 & $34.28 \%$ \\
\hline user29 & 1 & 2 & $35.71 \%$ \\
\hline user30 & 3 & 8 & $87.14 \%$ \\
\hline user31 & 2 & 7 & $81.42 \%$ \\
\hline user32 & Contributed & 8 & $87.14 \%$ \\
\hline
\end{tabular}

3.3.3. CfT forum super posters. In this session we classified super-posters to be learners who contributed in CfT discussion forum by posting 8 and above contributions. We applied a case analysis in the evaluation based on those that started a thread or post and made contributions in the forum discussions afterwards. We wanted to use the thread starters as a case analysis to be able to predict the behaviours of other contributors within the forum, also to draw a reasonable inference on the effects to better grades and commitment within the course. We 
also conducted an observation on the last user who actually was not a thread starter, but a contributor to the forums. Our main reason for doing this was to confirm our initial argument of frequent participation in forums could enhance better grades (as seen in Figure 10, Table 1 and 2). This was confirmed and there seems to be lots of better grades amongst those who started a thread and those who contributed in the discussion forums.

Table 2. Identified users extracted from Table1 who are in the tutor supported mode forum

\begin{tabular}{|c|c|c|c|}
\hline User & $\begin{array}{c}\text { No. of thread } \\
\text { started }\end{array}$ & $\begin{array}{c}\text { No. of forum } \\
\text { post }+ \\
\text { thread } \\
\text { started }\end{array}$ & $\begin{array}{c}\text { Average } \\
\text { course grade } \\
\mathbf{( \% )}\end{array}$ \\
\hline user12 & 2 & 4 & $91.31 \%$ \\
\hline user16 & 2 & 12 & $90 \%$ \\
\hline user29 & 1 & 2 & $35.71 \%$ \\
\hline user30 & 3 & 8 & $87.14 \%$ \\
\hline user31 & 2 & 7 & $81.42 \%$ \\
\hline user32 & Contributed & 8 & $87.14 \%$ \\
\hline
\end{tabular}

However, there was drawback; we observed learners with more than 3 forum contributions and have low scores been due to the fact that along the way they stop participating in the session quizzes [19]. They were only involved in one or two quizzes.

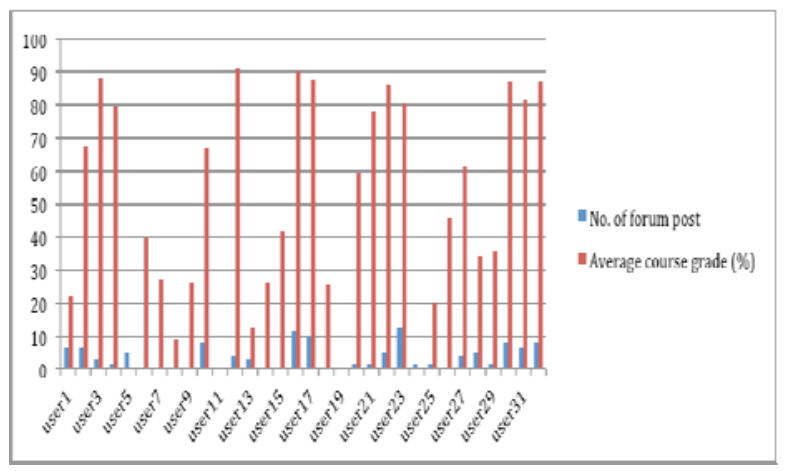

Figure 10. Showing forum post and better average grades within some high contributors

\section{Non-forum posters}

We randomly selected 10 anonymous users who have never participated in CfT forum all through to completion as seen in Table 3 and figure 11. These ten users represents the vast majority average performance of those that neither contributed nor started a thread.
Table 3. Illustrates randomly selected 10 users that never posted or contributed to a thread in CfT forum

\begin{tabular}{|c|c|c|}
\hline User & No. of forum post & $\begin{array}{c}\text { Average course } \\
\text { grade (\%) }\end{array}$ \\
\hline User1 & Nil & $2.14 \%$ \\
\hline User2 & Nil & $5.71 \%$ \\
\hline User3 & Nil & $0 \%$ \\
\hline User4 & Nil & $53.45 \%$ \\
\hline User5 & Nil & $5.71 \%$ \\
\hline User6 & Nil & $0 \%$ \\
\hline User7 & Nil & $0 \%$ \\
\hline User8 & Nil & $49.28 \%$ \\
\hline User9 & Nil & $0 \%$ \\
\hline User10 & Nil & $0 \%$ \\
\hline
\end{tabular}

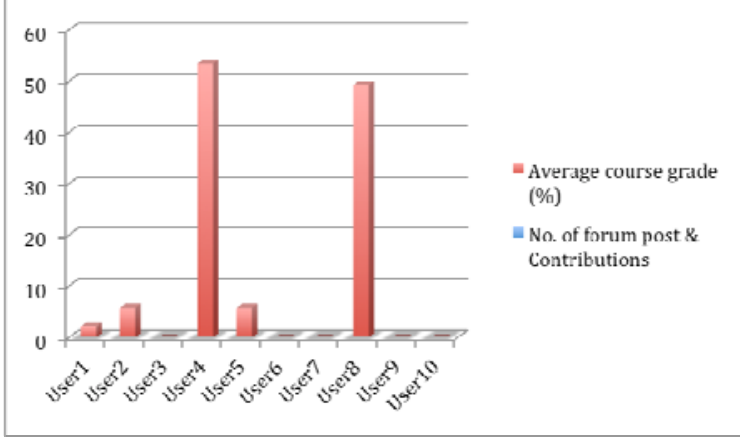

Figure 11. Showing randomly selected users that never participated in CfT forum

Figure 11 shows the highest score to be 53.455 (user4) and the lowest average score of $2.14 \%$ (user1).

\section{Discussion}

In both modes of delivery, levels of peer-to-peer discussion were low. Programming queries were the most common posts. This may because programming was found to be the most challenging aspect, but it is also the case that the hands-on nature of the programming labs means that problem areas are exposed.

In general, more active engagement strategies and the introduction of tasks related to forum posts are needed to encourage users both to initiate threads and to post replies to others. By the nature of the tutor-supported forum it is not surprising that posts were in general expecting a specific response from an "expert" rather than a peer and, when an answer was received, there was no further discussion. The two modes here emphasise a general point about conflicting use of forums: on the one hand, forums may be thought to encourage peer discussion and to promote engagement and active learning; on the other hand (and particularly in "technical" subjects) learners may be hoping simply to get a rapid and trustworthy response to a specific question. 
The latter may be useful for learners to make progress, but tends to underline dependency on the tutor and discourage further discussion.

\section{Conclusion and Further work}

There is an obvious difference here between a tutor-facilitated forum and a tutor-facilitated seminar. Despite the widespread use of forums there is still a lack of understanding of effect pedagogy. The rate for completion on the tutor-supported mode was higher than for those on the peer-supported mode. However, the additional facilities (both the forum and hang-outs with a tutor) were not highly used so the outcomes may be highly related to learners' motivation and commitment as evidenced by the choice of a mode requiring payment.

In many MOOC platforms, the forum is seen as one of the major support mechanisms, but usage of forums is noted by many as being quite low in general and often confined to a minority of participants. Forum participation has also been investigated by some as a predictor of imminent dropout [14]. However, even with more active engagement strategies to encourage participation, it seems that active forum behaviour appeals to some learners but not to others. There is evidence of "bad behaviour" on forums being an issue in a number of MOOCs but, even in well-behaved communities, there seems to be little evidence of support for students who started late or fall behind and it may even be the case that such students are discouraged by not being able to understand what is being discussed. We observed that the super posters in CfT were within the top in respect to good grades at the completion of the course.

Further work is needed to discover students' learning preferences and support different learning patterns. This applies both to the use of forums and to the wider issue of support. We intend to investigate pedagogy for effective use of MOOC forums and to explore aspects of adaptivity for MOOCs.

\section{Acknowledgment}

The first author wishes to acknowledge $\mathrm{Mr}$. Adakole. S. Onah's financial support in his research, and family members and friends for their moral support.

\section{References}

[1] Thomas, M. J. (2002). Learning within incoherent structures: The space of online discussion forums. Journal of Computer Assisted Learning, 18(3), 351-366.
[2] Boyatt, R., Joy, M., Rocks, C., \& Sinclair, J. (2013). What (use) is a MOOC? In 2nd Int. Workshop on Learning Technology for Education in Cloud (LTEC).

[3] Kizilcec, R. F., Piech, C., \& Schneider, E. (2013). Deconstructing disengagement: analyzing learner subpopulations in massive open online courses. In Proc. 3rd Int. Conf. on Learning Analytics and Knowledge (pp. 170-179). ACM.

[4] Baxter, J. A., \& Haycock, J. (2014). Roles and student identities in online large course forums: Implications for practice. The Int. Review of Research in Open and Distance Learning, 15(1).

[5] McGuire, R. (2013, August). Building a Sense of Community in MOOCs. Campus Technology, 31-33.

[6] Fini, A. (2009). The technological dimension of a massive open online course: The case of the CCK08 course tools. The Int. Review of Research in Open and Distance Learning, 10(5).

[7] Mak, S., Williams, R., and Mackness, J. (2010). Blogs and forums as communication and learning tools in a MOOC. In Networked Learing Conference, (pp. 275-285).

[8] Schweizer, B. (2013). Confessions of an Unreconstructed MOOC (h)er. THOUGHT \& ACTION, 61.

[9] Brinton, C. G., Chiang, M., Jain, S., Lam, H., Liu, Z., \& Wong, F. M. F. (2013). Learning about social learning in MOOCs: From statistical analysis to generative model. arXiv:1312.2159 [Accessed 20/7/14].

[10] MOOCs@Edinburgh Group. MOOCs@Edinburgh (2013): Report\#1, Available at: http://hdl.handle.net/1842/6683 [Accessed: 20/01/14].

[11] Yang, D., Sinha, T., Adamson, D., \& Rosé, C. P. (2013). Turn on, tune in, drop out: Anticipating student dropouts in massive open online courses. In Proc. NIPS Data-Driven Education Workshop.

[12] Huang, J., Dasgupta, A., Ghosh, A., Manning, J., \& Sanders, M. (2014). Superposter behavior in MOOC forums. In Proceedings of the first ACM conference on Learning@ scale conference (pp.117-126). ACM.

[13] Coetzee, D., Fox, A., Hearst, M. A., \& Hartmann, B. (2014). Should your MOOC forum use a reputation system? In Proc 17th ACM conf on computer on supported cooperative work \& social computing (pp.1176-1187).

[14] Onah, D.F.O., Sinclair, J., \& Boyatt, R. (2014). Dropout Rates of Massive Open Online Courses: Behavioural Patterns. EDULEARN14 Proceedings, pp. 5825-5834.

[15] Gillani, N., \& Eynon, R. (2014). Communication Patterns in Massively Open Online Courses. The Internet and Higher Education.

[16] Yang, Q. (2014). Students Motivation in Asynchronous Online Discussions with MOOC 
Mode. American J. of Educational Research, 2(5), 325330 .

[17] Coetzee, D., Fox, A., Hearst, M. A., \& Hartmann, B. (2014, February). Should your MOOC forum use a reputation system?. In Proceedings of the 17th ACM conference on Computer supported cooperative work \& social computing (pp. 1176-1187). ACM.

[18] Cheng, C. K., Paré, D. E., Collimore, L. M., \& Joordens, S. (2011). Assessing the effectiveness of a voluntary online discussion forum on improving students' course performance. Computers \& Education, 56(1), 253261.

[19] Onah, D.F.O., Sinclair, J., Boyatt, R., \& Foss, J. (2014) Massive Open Online Courses: Learners Participation, ICERI2014 Proceedings, pp. 23482356. 